\title{
The Relationship between End Tidal Carbon Dioxide and Arterial Carbon Dioxide during Controlled Hypotensive Anaesthesia
}

\author{
Syed Shujat Ali Alexander Dubikaitis Abdul Raheem Al Qattan \\ Department of Anaesthesia and Intensive Care, Al Sabah Hospital, Kuwait
}

\section{Key Words}

Arterial blood pressure $\cdot$ Controlled ventilation $\cdot$ End tidal carbon dioxide $\cdot$ Hypotension - Middle ear surgery . Physiological dead space

\begin{abstract}
Objectives: To prospectively assess the magnitude of changes in the arterial-to-end tidal carbon dioxide gradient $\left[\mathrm{P}(\mathrm{a}-\mathrm{ET}) \mathrm{CO}_{2}\right]$ as well as in the ratio of physiological dead space to tidal volume $\left(\mathrm{Vd}_{\text {phys }} / \mathrm{Vt}\right)$ during controlled hypotensive anaesthesia, and to evaluate whether or not ventilatory requirements remain unaltered during this procedure. Subjects and Methods: Twelve adult patients with American Society of Anesthesiologists' physical status I and II undergoing middle ear surgery were selected. A standard anaesthetic procedure was followed for all cases, using thiopental sodium, succinylcholine, fentanyl, atracurium and $60 \% \mathrm{~N}_{2} \mathrm{O}$ in $40 \%$ oxygen supplemented with isoflurane. Mean arterial blood pressure (MAP) was reduced to $60 \pm 5 \mathrm{~mm} \mathrm{Hg}$ in all patients using a sodium nitroprusside infusion. The end tidal (ET) $\mathrm{CO}_{2}, \mathrm{PaCO}_{2}, \mathrm{MAP}$, peak airway pressure, plateau pressure and expiratory minute volume were recorded during a period of normal arterial blood pressure (time 1) and during hypotension (time 2). Results: A significant decrease in $\mathrm{PaCO}_{2}(7 \%)$ and $\mathrm{ETCO}_{2}(17 \%)$ from time 1 to time $2(p<0.01)$ was noted, as was a significant increase in $\mathrm{P}(\mathrm{a}-\mathrm{ET}) \mathrm{CO}_{2}(48 \%)$ and in the $\mathrm{Vd}_{\text {phys }} / \mathrm{Vt}$ ratio $(41.17 \%)(p<0.01)$ during the same period. Conclusion:
\end{abstract}

The decrease in $\mathrm{ETCO}_{2}$ does not reflect the changes in $\mathrm{PaCO}_{2}$. The larger decrease in $\mathrm{ETCO}_{2}$ is mainly due to the increase in the $\mathrm{Vd}_{\text {phys }} / \mathrm{Vt}$ ratio. During anaesthesia, once normocapnia is achieved with normal arterial blood pressure, there is hardly any need to change the ventilation after initiation of controlled hypotension.

Copyright @ $@ 2002$ S. Karger AG, Basel

\section{Introduction}

End tidal carbon dioxide $\left(\mathrm{ETCO}_{2}\right)$ is an indispensable monitor for ensuring safety in modern anaesthetic practice. However, it is not reliable for determining the adequacy of ventilation during low cardiac output because the arterial-to-end tidal carbon dioxide gradient [P(aET) $\mathrm{CO}_{2}$ ] changes during these conditions. The changes are due to alterations in the ratio of physiological dead space to tidal volume $\left(\mathrm{Vd}_{\text {phys }} / \mathrm{Vt}\right)$ and that of ventilation to perfusion (V/Q) [1].

When cardiac output is low, as seen during controlled hypotensive anaesthesia, the $\mathrm{ETCO}_{2}$ may decrease, leading to changes in $\mathrm{P}(\mathrm{a}-\mathrm{ET}) \mathrm{CO}_{2}$. These changes may lead to erroneous resetting of the parameters of ventilation. Neither the ventilatory requirements during controlled lowflow states like hypotensive anaesthesia nor the relationship between changes in perfusion at steady-state ventilation and $\mathrm{P}(\mathrm{a}-\mathrm{ET}) \mathrm{CO}_{2}$ have been evaluated. Hence, the objectives of the present study are to prospectively assess the magnitude of changes in $\mathrm{P}(\mathrm{a}-\mathrm{ET}) \mathrm{CO}_{2}$ and the $\mathrm{Vd}_{\text {phys }} /$

\section{KARGER}

Fax +41613061234

E-Mail karger@karger.ch

www. karger.com

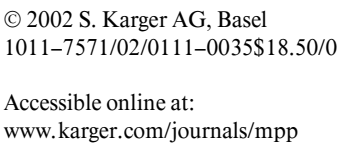

Dr. Syed Shujat Ali

Department of Anaesthesia and Intensive Care, Al Sabah Hospital

PO Box 4078, Safat 13041 (Kuwait)

Tel. +965 4832088, Fax +9654818213

E-Mail drshujatali@yahoo.com 
$\mathrm{Vt}$ ratio and to evaluate the correlation between $\mathrm{ETCO}_{2}$ and mean arterial blood pressure (MAP) at steady-state ventilation during controlled hypotensive anaesthesia.

\section{Subjects and Methods}

Twelve patients aged 20-50 years undergoing elective middle ear surgery ( 7 men and 5 women) with physical status I and II as per the American Society of Anesthesiologists' classification were included in the study. The study was approved by the Scientific Subcommittee of the Council of Anaesthesia and Intensive Care, Ministry of Health, Kuwait.

A standard anaesthetic procedure was followed for all patients. They were premedicated orally with diazepam $(0.15 \mathrm{mg} / \mathrm{kg})$ on the morning of surgery. Standard monitoring included electrocardiogram, pulse oximeter, capnograph, non-invasive blood pressure, temperature and neuromuscular block with nerve stimulator (TOF guard, Organon). The Ohmeda modulus CD anaesthesia system was calibrated before the start of anaesthesia. Patients were induced with fentanyl $(1 \mu \mathrm{g} / \mathrm{kg})$, thiopental sodium $(5-7 \mathrm{mg} / \mathrm{kg})$ and succinylcholine $(1.5 \mathrm{mg} / \mathrm{kg})$, and endotracheal intubation was done after complete relaxation, followed by $60 \% \mathrm{~N}_{2} \mathrm{O}$ in $40 \% \mathrm{O}_{2}$ supplemented with isoflurane as required. Neuromuscular blockade was achieved with atracurium $(0.5 \mathrm{mg} / \mathrm{kg})$ followed by intermittent boluses as indicated by the nerve stimulator. Patients were ventilated mechanically with a tidal volume of 7-10 ml/kg to achieve an $\mathrm{ETCO}_{2}$ of $35-40 \mathrm{~mm} \mathrm{Hg}$. Peak airway pressure, plateau pressure and expiratory minute volume were measured. After achieving a steady-state $\mathrm{ETCO}_{2}$ for $10 \mathrm{~min}$, an arterial blood sample was acquired with a micro-sampler (time 1) and the blood gases were measured on a precalibrated (AVL Omni) blood gas analyzer. At the start of the surgery, an additional dose of fentanyl $(1-2 \mu \mathrm{g} / \mathrm{kg})$ was given, and hypotension was induced with sodium nitroprusside up to a maximum dose of $4 \mu \mathrm{g} / \mathrm{kg} / \mathrm{min}$ to achieve a MAP of $60 \mathrm{~mm} \mathrm{Hg}( \pm 5 \mathrm{~mm} \mathrm{Hg})$. When the blood pressure remained steady for $10 \mathrm{~min}, \mathrm{ETCO}_{2}$ was recorded and a second arterial sample was analyzed for blood gases (time 2). Throughout the procedure, the ventilator parameters of the patients were kept unchanged.

The $\mathrm{P}(\mathrm{a}-\mathrm{ET}) \mathrm{CO}_{2}$ was estimated at two different times with two different MAPs. Lung compliance was estimated and the $\mathrm{Vd}_{\text {phys }} / \mathrm{Vt}$ ratio was calculated with Enghoff's modification of Bohr's equation and the changes were recorded. Delta $\mathrm{ETCO}_{2}$ and delta MAP were measured. Data were analysed using Student's paired t test. All values were expressed as mean with standard deviation. $\mathrm{p}<0.01$ was considered significant.

\section{Results}

The mean age and the body weight of the patients were $34.5 \pm 12.31$ years and $63.83 \pm 12.71 \mathrm{~kg}$, respectively.

The $\mathrm{PaCO}_{2}$ decreased from a mean of $41 \pm 1.94$ to $38.2 \pm 2.16 \mathrm{~mm} \mathrm{Hg}$, which occurred between time 1 with normal blood pressure (MAP $83.7 \pm 9.67 \mathrm{~mm} \mathrm{Hg}$ ) and time 2 with controlled hypotension (MAP $62.9 \pm 2.02$ $\mathrm{mm} \mathrm{Hg}$ ). The $\mathrm{ETCO}_{2}$ decreased to a greater extent from a

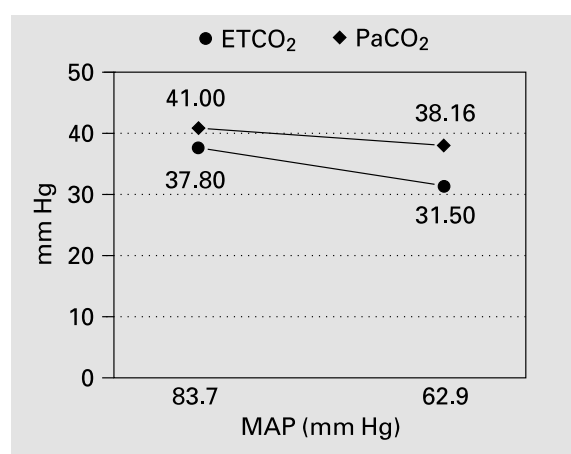

Fig. 1. $\mathrm{PaCO}_{2}$ and $\mathrm{ETCO}_{2}$ during normal $\operatorname{MAP}(83.7 \pm 9.6 \mathrm{~mm} \mathrm{Hg})$ (time 1$)$ and during controlled hypotension $(62.9 \pm 2.02 \mathrm{~mm}$ $\mathrm{Hg})($ time 2) $(\mathrm{p}<0.01)$.

mean of $37.8 \pm 1.02$ to $32.5 \pm 1.83 \mathrm{~mm} \mathrm{Hg}(\mathrm{p}<0.01)$ during this period (fig. 1). The $\mathrm{P}(\mathrm{a}-\mathrm{ET}) \mathrm{CO}_{2}$ increased significantly from a mean of $3.2 \pm 1.7$ to $6.7 \pm 2.3 \mathrm{~mm} \mathrm{Hg}$ (p<0.01) (fig. 2).

When the MAP decreased by $25 \%, \mathrm{PaCO}_{2}$ decreased $7 \%$ and $\mathrm{ETCO}_{2}$ decreased by $17 \%$, while the $\mathrm{P}(\mathrm{a}-\mathrm{ET}) \mathrm{CO}_{2}$ gradient increased by $48 \%$. This increase in $\mathrm{P}(\mathrm{a}-\mathrm{ET}) \mathrm{CO}_{2}$ gradient was statistically significant $(\mathrm{p}<0.01)$ (fig. 3 ).

There was no change in lung compliance. The $\mathrm{Vd}_{\text {phys }} /$ $\mathrm{Vt}$ ratio increased significantly from 0.07 to 0.17 $(41.17 \%)(\mathrm{p}<0.01)($ table 1$)$. No correlation between MAP and $\mathrm{ETCO}_{2}(\mathrm{R}=0.57)$ was found.

\section{Discussion}

In this study, we investigated the impact of induced hypotension on the gradient between $\mathrm{PaCO}_{2}$ and $\mathrm{ETCO}_{2}$. The data showed that during MAP reduction from $83.7 \pm$ 9.67 to $62.9 \pm 2.02 \mathrm{~mm} \mathrm{Hg}$, the gradient between $\mathrm{PaCO}_{2}$ and $\mathrm{ETCO}_{2}$ is increased twofold. We used a moderate degree of hypotensive anaesthesia with the MAP constantly maintained between 60 and $65 \mathrm{~mm} \mathrm{Hg}$. The level of MAP produced satisfactory operating conditions. The changes in $\mathrm{ETCO}_{2}$ in our study did not accurately predict the changes in $\mathrm{PaCO}_{2}$. Various studies have suggested that $\mathrm{ETCO}_{2}$ does not provide a stable reflection of $\mathrm{PaCO}_{2}$ in certain clinical situations [2-4]. Moderate controlled hypotension under anaesthesia may cause a modest fall in cardiac output. As the pulmonary blood flow decreases due to the fall in cardiac output, it causes a loss of homeostasis at the alveolar/capillary level and a ventilation/perfusion mismatch. An increase in V/Q may cause an 


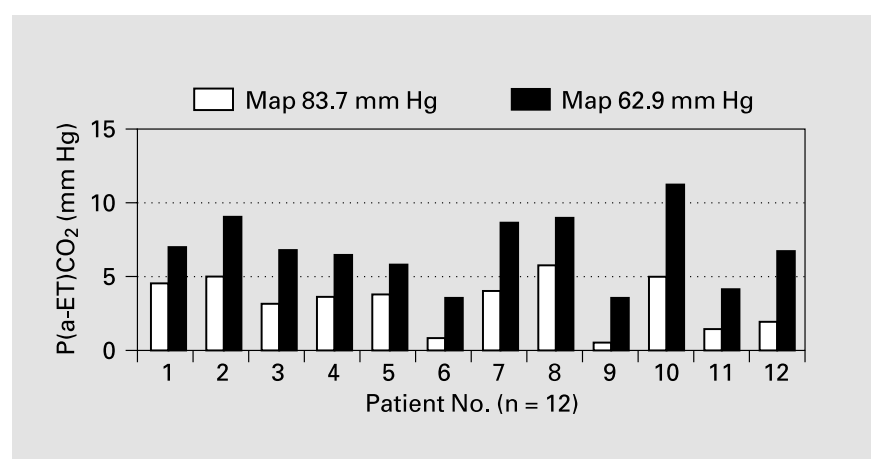

Fig. 2. $\mathrm{P}(\mathrm{a}-\mathrm{ET}) \mathrm{CO}_{2}$ values for the individual patients during normal MAP $(83.7 \pm 9.6 \mathrm{~mm} \mathrm{Hg})$ (time 1$)$ and during controlled hypotension $(62.9 \pm 2.02 \mathrm{~mm} \mathrm{Hg})($ time 2$)(\mathrm{p}<0.01)$.

Table 1. Lung compliance and $\mathrm{Vd}_{\text {phys }} / \mathrm{Vt}$ ratio during general anaesthesia with normal MAP (time 1) and with controlled hypotension (time 2)

\begin{tabular}{lcc}
\hline & Time 1 & Time 2 \\
\hline MAP, mm Hg & $83.7(9.67)$ & $62.9(2.02)$ \\
Lung compliance, $\mathrm{ml} / \mathrm{cm} \mathrm{H}_{2} \mathrm{O}$ & $25.99(5.07)$ & $25.71(4.71)$ \\
$\mathrm{Vd}_{\text {phys }} /$ Vt ratio & $0.07(0.04)$ & $0.17(0.05)$ \\
\hline
\end{tabular}

Results are shown as means with the SD in parentheses.

increase in the amount of shunted blood, which decreases $\mathrm{ETCO}_{2}$ and increases the gradient if the arterial $\mathrm{CO}_{2}$ does not change appreciably. Since, in our study, $\mathrm{PaCO}_{2}$ remained in the clinical range, we did not alter the ventilator settings. A rise in the V/Q ratio, such as may occur following a fall in pulmonary blood flow, can cause an increase in physiological dead space. In this study, the $\mathrm{Vd}_{\text {phys }} / \mathrm{Vt}$ ratio doubled during the controlled hypotensive period. An increase in $\mathrm{P}(\mathrm{a}-\mathrm{ET}) \mathrm{CO}_{2}$ gradient also occurs when dead space ventilation increases.

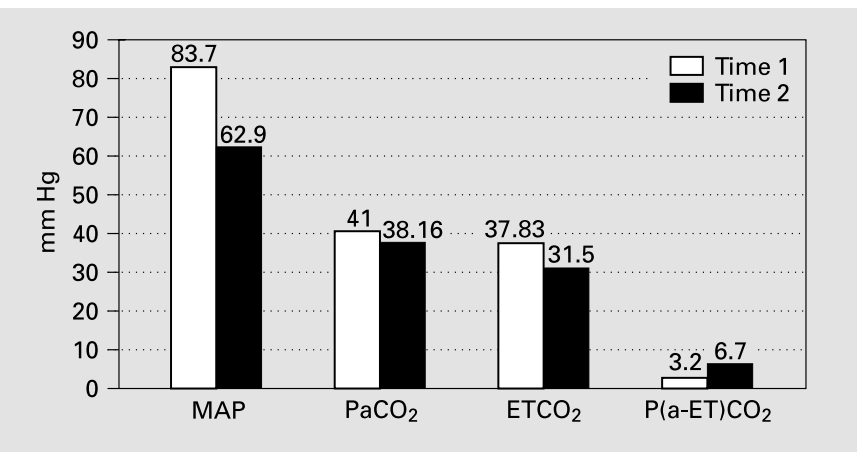

Fig. 3. Changes in $\mathrm{PaCO}_{2}, \mathrm{ETCO}_{2}$ and $\mathrm{P}(\mathrm{a}-\mathrm{ET}) \mathrm{CO}_{2}$ at two different MAPs. P(a-ET) $\mathrm{CO}_{2}$ increased significantly $(\mathrm{p}<0.01)$.

Although capnography is a standard monitoring technology, traditional monitoring of arterial blood gases is also required to prevent hypoventilation during controlled hypotensive anaesthesia, where the physiological shunt and alveolar dead space are high [5]. Nevertheless, monitoring of $\mathrm{ETCO}_{2}$ identifies decreases in cardiac output instantly during low-flow and circulatory shock states [6]. Further studies measuring cardiac output instead of arterial blood pressure during controlled hypotensive anaesthesia are required.

\section{Conclusion}

During anaesthesia, once normocapnia is achieved with normal arterial blood pressures, there is hardly any need to decrease ventilation after induction of controlled hypotension. $\mathrm{ETCO}_{2}$ does not reflect changes in $\mathrm{PaCO}_{2}$, because as $\mathrm{P}(\mathrm{a}-\mathrm{ET}) \mathrm{CO}_{2}$ is increased, $\mathrm{PaCO}_{2}$ remains in the clinically acceptable range. The larger decrease in $\mathrm{ETCO}_{2}$ during controlled hypotension is mainly due to the increase in the $\mathrm{Vd}_{\text {phys }} / \mathrm{Vt}$ and $\mathrm{V} / \mathrm{Q}$ ratios.

\section{References}

1 Shankar KB, Moseley H, Kumar Y: Relationship between $\mathrm{PaCO}_{2}-\mathrm{PETCO}_{2}$ gradient and physiological dead space. Can J Anaesth 1991; 38:1072-1074.

2 Russell GB, Graybeal JM: The arterial to endtidal carbon dioxide difference in neurosurgical patients during craniotomy. Anesth Analg 1995;81:806-810.

Changes in $\mathrm{CO}_{2}$ during Controlled

Hypotensive Anaesthesia
3 Shankar KB, Moseley H, Kumar Y, Vemula V: Arterial to end tidal carbon dioxide tension difference during caesarean section anaesthesia. Anaesthesia 1986;41:698-702.

4 Casati A, Salvo I, Torri G, Calderini E: Arterial to end-tidal carbon dioxide gradient and physiological dead space monitoring during general anaesthesia: Effects of patients' position. Minerva Anestesiol 1997;63:177-182.
5 Eckenhoff JE: Deliberate hypotension. Anesthesiology 1978;48:87-88.

6 Jin X, Weil MH, Tang W, Povoas H, Pernat A, Xie J, Bisera J: End-tidal carbon dioxide as a noninvasive indicator of cardiac index during circulatory shock. Crit Care Med 2000;28: 2415-2419. 